\title{
Factors Affecting Maternal Birth Preparedness: Evidence from Salatiga, Cental Java
}

\author{
Ana Yuliana1), Bhisma Murti1), Hanung Prasetya') \\ 1)Masters Program in Public Health, Universitas Sebelas Maret \\ ${ }^{2)}$ School of Health Polytechnics Surakarta
}

\begin{abstract}
Background: Maternal unpreparedness in facing childbirth is one of the factors causing the high maternal mortality rate (AKI). To support efforts to accelerate the reduction of MMR, preparation of childbirth is an important matter that must be improved. Pregnant women class is an activity to prepare the mother physically and psychologically in facing the delivery. The purpose of this study was to determine the factors that influence preparation for childbirth in pregnant women, including: the role of midwives, motivation of pregnant women and utilization of pregnant classes.

Subjects and Method: This was an analytic observational study with a cross sectional design. The study was conducted in 6 community health centers in Salatiga, from June to July 2018. A sample of 120 mothers was selected by total sampling. The dependent variable was birth preparation. The independent variables were motivation, midwife role, and utilization of pregnant class. The data were collected by questionnaire and analyzed by a multiple linear regression.

Results: Birth preparedness was increased with strong midwife role $(\mathrm{b}=2.82 ; 95 \% \mathrm{CI}=-0.45$ to 5.68; $\mathrm{p}=0.054)$, strong motivation $(\mathrm{b}=4.12 ; 95 \% \mathrm{CI}=0.97$ to $7.27 ; \mathrm{p}=0.011)$, and utilization of pregnant class $(b=3.90 ; 95 \% \mathrm{CI}=0.66$ to $7.13 ; \mathrm{p}=0.019)$.

Conclusions: Birth preparedness is increased with strong midwife role, strong motivation, and utilization of pregnant class.
\end{abstract}

Keywords: birth preparedness, motivation, midwife role, pregnancy class, pregnant women

\section{Correspondence:}

Ana Yuliana. Masters Program in Public Health, Universitas Sebelas Maret, Jl. Ir. Sutami No. 36 A, Surakarta 57126, Central Java. Email: aishabilqisnugroho@gmail.com. Mobile: +62139321543.

\section{BACKGROUND}

Maternal Mortality Rate (MMR) in Indonesia is still relatively high compared to other developing countries in the world, namely 305 / 100,000 lives birth (Ministry of Health RI, 2015). Some efforts have been made by the government to reduce the MMR, but from the results of the 2015 MDG evaluation, these efforts have not been in line with the targets set by the government. Several efforts have been made to reduce MMR through the integration of several related programs through several programs, including the class of pregnant women (Ministry of Health RI, 2011).
Maternal unpreparedness in facing the childbirth is one of the factors causing the high maternal mortality rate (AKI). To support efforts to accelerate the reduction of MMR, preparation of childbirth is an important matter that must be improved. Maternal preparation for delivery can be done through a class of pregnant women, where by attending classes for pregnant women the mother can get complete, clear, and structured information about the care of pregnancy, childbirth, postpartum and newborn care (Lucia et al., 2015).

A study by Rasouli et al. (2016) about high motivation for pregnant women to actively participate in a class of pregnant women is crucial for the realization of a 
natural and smooth delivery through the vagina.

Cornally et al. (2014) showed that the expectation of physiological delivery in pregnant women is strongly influenced by previous birth perception and experience. A positive experience will motivate pregnant women to be more ready to face the childbirth. Likewise, previous labor trauma makes pregnant women feel anxious and worried about the next delivery. Birth preparation is strongly influenced by husband, family, and midwives support who can provide high motivation to prepare pregnant women in the face of childbirth (Ulstad, et al., 2016).

Midwives play an important role in providing services in the form of education for mothers in the form of classes for pregnant women to assist in making appropriate maternity preparation decisions for pregnant women. According to research from Kathrin and Wendy (2012), classes of pregnant women conducted in the country of Canada concluded that there was a relationship between participation in pregnant women in pregnancy class activities, with fear of childbirth and anxiety. Pregnant women who take classes for pregnant women have lower levels of anxiety compared to pregnant women who do not participate in the class of pregnant women effectively.

Soumya and Bindhu (2016) educational activities for pregnant women in India carried out on pregnant women with 36 weeks' gestation effective to reduce pain and anxiety in pregnant women in facing the natural childbirth. Activities carried out in the maternal class include screening of maternity videos to train breathing and a comfortable position during childbirth.

The cause of maternal death is still dominated by childbirth with the highest factor in bleeding, until the occurrence of infection, the need for efforts and strategies for health services for pregnant women that are easy to reach. Pregnant women class is one of the activities facilitated by health centers with the general purpose of holding a pregnant mother class to increase knowledge, change maternal attitudes and behaviors so that they understand about pregnancy so that they can prepare their pregnancies better.

The purpose of this study was to determine the risk factors that affect preparation in facing the childbirth in Salatiga.

\section{SUBJECTS AND METHOD \\ 1. Study Design}

This was an analytic observational study with a cross sectional design. The study was conducted in Salatiga, from March to June 2018.

\section{Population and Samples}

The population of this study were 120 pregnant women who were divided into 6 Puskesmas in Salatiga. The sampling method used in this study was total sampling.

\section{Study Variables}

The independent variables were the role of midwife, motivation, and utilization of pregnant class. The dependent variable was birth preparedness. The inclusion criteria in this study were pregnant women living in Salatiga with a gestational age of 24-32 weeks.

\section{Operational Definition of Variables}

Midwife's role was defined as the behavior of the midwife according to its function in helping pregnant women. The role of midwives in providing services to their clients is 3 , namely as a facilitator by applying themselves to become a technical guide or tutor and empowering those who are being accompanied to grow and develop towards the desired goals. The role of 
educator is by providing education to individuals, families and communities during the preconception period to public health maintenance. The role of executor is by providing community midwifery services.

Motivation arises from the existence of knowledge, beliefs, beliefs, available facilities and perceived needs. Motivation of pregnant women was a situation in a pregnant woman that encourages the desire to become pregnant. Pregnant women who have good knowledge about pregnancy classes, they have the right and right thoughts about the class of pregnancy. They know that a pregnant class is a learning tool that is very useful for pregnant women related to their pregnancy, thus motivating them to take pregnancy classes. Pregnant women who regularly use pregnant classes will better prepare themselves for childbirth.

The utilization of pregnant classes was defined as a government program to prepare pregnant women both physically and psychologically through increasing knowledge and sharing previous birth experiences through face-to-face interaction to prepare for natural childbirth. Pregnant women class is a group learning activity for pregnant women which aims to increase maternal knowledge and skills regarding pregnancy, pregnancy care, childbirth, postnatal care, newborn care, myths, and sexually transmitted diseases.

Birth preparation was defined as an action plan made by mothers, family Table 1. The Characteristics of Study Subject

\begin{tabular}{llcc}
\hline Characteristics & & n = 120 & Percentage (\%) \\
\hline Employment & Employed & 36 & 30 \\
Parity & Unemployed & 84 & 70 \\
& Primiparous & 42 & 35 \\
Age & Multiparous & 78 & 65 \\
& High Risk & 24 & 20 \\
\hline
\end{tabular}

members and midwives. The existence of a birth plan will reduce anxiety and confusion when faced with labor. There are 4 childbirth preparations for pregnant women, namely physical preparation must be matured early in pregnancy because the labor process is tiring for pregnant women. The psychological preparation means that pregnant women are advised not to harbor fear. Knowledge of childbirth and pregnancy classes is needed so that pregnant women are ready to mentally face childbirth. Financial preparation in the form of savings for labor costs and cultural preparation that is the mother must know the customs, traditions and habits of life that are not good for pregnancy and try to prevent it.

\section{Research Ethics}

This study has obtained an ethical clearance from the Ethical Health Research Ethics Commissio of Dr. Moewardi hospital, Surakarta.

\section{Data Analysis}

The characteristics in this study were categorical data which described in $\mathrm{n}$, and percent (\%). The effect of independent and dependent variables was analyzed by multiple linear regression analysis model.

\section{RESULTS \\ 1. The characteristic of study subjects Based on Table 1, it can be seen that Most of the study subjects was multiparous $(78$, $65 \%)$, were at reproductive age $(96,80 \%)$, and working at home $(84,70 \%)$.}


Journal of Maternal and Child Health (2019), 4(1): 55-61

https://doi.org/10.26911/thejmch.2019.04.01.08

\section{The results of univariate analysis}

Table 2. Univariate Analysis

\begin{tabular}{llcc}
\hline \multicolumn{1}{c}{ Variables } & Category & n= 120 & Percentage (\%) \\
\hline The Role of Midwives & Good & 69 & 57.5 \\
& Poor & 51 & 42.5 \\
Pregnant Women's Motivation & High & 77 & 64.2 \\
& Low & 43 & 35.8 \\
\multirow{2}{*}{ The Utilization of Pregnancy Class } & High & 78 & 65.0 \\
& Low & 42 & 35.0 \\
Birth Preparedness & Good & 49 & 40.8 \\
& Poor & 71 & 59.2 \\
\hline
\end{tabular}

Table 2 showed that most of the midwives roles were good $(69,57.5 \%)$. Most of the pregnant women had strong motivation $(77$,
64.2\%), the utilization of pregnancy class was high $(78,65 \%)$, and mother's birth preparation was good $(71,59.2 \%)$.

Table 3. The results of multiple linear regression analysis of the effects of midwives' role, motivation, and the utilization of pregnancy class on birth preparedness

\begin{tabular}{|c|c|c|c|c|}
\hline \multirow{2}{*}{$\begin{array}{l}\text { Independent } \\
\text { Variables }\end{array}$} & \multirow[b]{2}{*}{ b } & \multicolumn{2}{|c|}{$95 \% \mathrm{CI}$} & \multirow[b]{2}{*}{$\mathbf{p}$} \\
\hline & & Lower Limit & Upper Limit & \\
\hline (Constant) & 53.60 & 47.95 & 59.253 & $<0.001$ \\
\hline Midwives Roles & 2.82 & -0.45 & 5.68 & 0.054 \\
\hline Motivation & 4.12 & 0.97 & 7.27 & 0.011 \\
\hline $\begin{array}{l}\text { The Utilization of } \\
\text { Pregnancy Class }\end{array}$ & 3.90 & 0.66 & 7.13 & 0.019 \\
\hline N Observation & 120 & & & \\
\hline Adjusted R Square & $24 \%$ & & & \\
\hline $\mathrm{p}$ & $<0.001$ & & & \\
\hline
\end{tabular}

The results of Table 3 above showed that the variables of midwives, pregnant women's motivation, and the utilization of pregnancy classes affected birth preparedness by $25.9 \%$, where the $74.1 \%$ was affected by other factors outside the research model.

There was a significant effect between the role of midwives and birth preparedness $(\mathrm{b}=2.82,95 \% \mathrm{CI}=-0.45$ to $5.68, \mathrm{p}=$ 0.054).

There was a significant effect between pregnant women's motivation and birth preparedness $(b=4.12 ; 95 \% \mathrm{CI}=0.97$ to $7.27 ; \mathrm{p}=0.011$ ) the higher the motivation of pregnant women, the better the birth preparedness.

There was a significant effect between pregnancy classes utilization and birth preparedness $(b=3.90 ; 95 \% \mathrm{CI}=0.66$ to 7.13; $\mathrm{p}=0.019)$.

\section{DISCUSSIONS}

\section{The Effect of Midwives Role on Birth Preparedness}

The result showed that There was a significant effect between the role of midwives and birth preparedness. The better the midwives roles, the better the birth preparedness.

This statement was strengthened by a study done in Greece about the role of midwife in preparing pregnant women in facing the labor. In facing the labor, pregnant women have the need for friendship, empathy, and help from the midwives. Supports from sustainable midwives provide greater benefits than intermittent 
support. Pregnant women need support from midwives from the beginning of pregnancy until the time of delivery. Pregnant women who get positive emotional, physical, and information supports would be more calm in dealing with labor. In this case, the midwife has a unique position to educate pregnant women in doing their new role as parents (Iliadou, 2012).

A study done in Irlandia by Cornally et al. (2014) concluded that the perception of pregnant women regarding childbirth was further influenced by the role of midwives through antenatal classes. In antenatal classes, midwives participated effectively to mediate in providing support for pregnant women to prepare for the birth of their babies.

Qualitative research on 16 midwives and 16 pregnant women in Iran stated that effective communication and emotional support between midwives and pregnant women reduced sectio caesarea deliveries. Continuous service in pregnant women has a positive effect on the birth of a baby physiologically (Attarha et al., 2016). Similar study was done by Dahl Berg et al. (2016) in Norwegia, the results of the study showed that midwives have an important role in motivating pregnant women to give birth normally.

Based on several studies that have been stated, it can be concluded that the role of midwives has a positive effect on maternal preparation in facing the labor through holistic education and services.

\section{The Effect of Pregnant Women's Motivation on Birth Preparedness}

The result showed that there was a significant effect between pregnant women's motivation and birth preparedness. This results was in line with a study by Dixon et al. (2013), which showed that there was a relationship between Neurohormones which regulate the emotions of pregnant women related to maternal behavior in facing the labor. The behavior was associated with instinctive emotions that formed maternal motivation to face spontaneous labor.

Pregnant women described external motivation for adopting health behaviors, especially behaviors for the benefit of their labor. A study conducted in the USA confirmed that internal motivation affected the changes in maternal behavior before the birth process and developed internal motivation to give birth normally (Kocher et al., 2017).

According to a study by Nillson et al. (2017), it concluded that there was a relationship between pregnant women's motivation and labor experiences. Pregnant women who have negative experiences in the past have high motivation to prepare for the next delivery carefully.

From several existing studies, it can be concluded that the motivation of pregnant women was in line with birth preparedness. The stronger motivation, the better birth preparedness.

\section{The Effect of Pregnancy Class Utilization on Birth Preparedness}

The result of this study showed that there was a significant effect between pregnancy class utilization and birth preparedness. The higher the utilization of the pregnancy class, the better the birth preparation for pregnant women.

Experimental study conducted by Hajipour et al. (2017) in Iran, which examined mental health, vitality, and the role of emotional function in pregnant women with case groups and control groups before and after the prenatal class showed that pregnant women who received prenatal education had better scores and mental health to prepare for their childbirth than pregnant women who did not attend prenatal classes. Therefore, prenatal 
education was needed to improve the health and quality of life of pregnant women.

According to a study by Kurdy et al. (2017) in Egypt, it stated that pregnant women who attend prenatal classes have greater self-efficacy in facing the labor and have low labor pain. Prenatal classes provide an opportunity for primiparous mothers to improve their self-efficacy in preparing for labor and reducing labor pain. The study recommend the importance of designing and implementing prenatal classes as an important component of standard antenatal care in various public hospitals in Egypt that were affiliated for labor preparation, especially in primigravid mothers.

This was strengthened by a study done by Nazik et al. (2017) in Iran which examined the benefits of prenatal classes on 246 pregnant women consisting of 113 case groups and 133 control groups, the result showed that prenatal classes had an effect on labor preparation and birth delivery. The results of the study showed that birth preparedness in the group that took part in the prenatal class had a higher labor preparation than the control group significantly.

Research conducted in Turkey by Pinar et al. (2016) discussed the benefits of maternal classes that have a positive impact on pregnant women through increased knowledge of pregnancy, labor, postpartum, and newborn care so that pregnant women were effectively able to adapt to physical and psychological changes before labor.

Redshaw and Henderson (2013) stated that pregnancy classes have the benefit of preparing mothers as parents emotionally and psychologically in facing the pregnancy, labor, and parenting, therefore, they were more confident of their role as parents.

Based on the description above, it can be concluded that there was a positive effect between the utilization of pregnancy classes and birth preparedness of pregnant women in Salatiga.

\section{REFERENCES}

Attarha M, Keshavarz Z, Bakhtiari M, Jamilian M (2016). The Outcome of Midwife-Mother Relationship in Delivery Room: a Qualitative Content Analysis. http://dx.doi.org/10.4236/health.2016.8403.

Cornally P, Canty G (2014). Exloring Women's Experiences of Care in Labour Jurnal Evidence Based Midwifery 12 (3): 88-89.

Dahlberg U, Persen J, Skogas AK, Selboe AT (2016). How Can Midwives Promote a Normal Birth and Positive Birth Experience of First-Time Norwegian Mothers. The Journals of Sexual and Reproductive Healthcare Elsevier. Http://dx.doi.org/10.1016/j.srhc.2015.08.011.

Dixon L, Skinner J, Foureur M (2013). Women's Perspectives of The Stages and Phases of Labour. New Zealand College of Midwifery Journal, 48, 1523. Http://dx.doi.org/10.12784/nzco$\min 148.2013 \cdot 3 \cdot 15-23$.

Eames C (2013). Midwives Role in Preparing Women for Birth. British Journal of Midwifery. 12(7). https://doi.org/10.12968/bjom.2004.112.7.13322.

Hajipour L, Amiri ZM, Montazeri A, Torkan B, Tabaghdehi MH (2017). The Effect of Prenatal Classes on the Quality of Life in Pregnant Women. Journal of Holistic Nursing and Midwifery.

Iliadou M (2012). Supporting Women in Labour. Health Science Journal 6(3). 
Kathrin H, Wendy (2012). Childbirth Education and Obstetric Interventions Among Low-Risk Canadian Women: Is there a Connection?. The Journal of Perinatal Education. Http://dx.doi.org/10.1891/1058-1243.21.4.229.

Kemenkes RI (2011). Pedoman Pelaksanaan Kelas Ibu Hamil Tahun 2011. Jakarta: Kementerian Kesehatan RI. (2015). Angka Kematian Ibu dan Bayi Tahun 2015. Jakarta: Kementerian Kesehatan RI.

Kocher EL, Lamb JMS, McGarvey ST, Faiai M, Hawley NL (2018). Conceptions of Pregnancy Health and Motivations for Halthful Behavior Change among Women in American Samoa. Journals of Women and Health Elsevier.

Kurdi RE, Hassan S, Hassan NF, Nemer AE (2-17). Antenatal Education on Childbirth Self-Efficacy for Egyptian Primiparous Women: Randomized Control Trial. Journal of Nuring and Health Science, 6(4). www.iosjournals.org.

Lucia S, Purwandari, Pesak E (2015). Pengaruh Pelaksanaan Kelas Ibu Hamil Terhadap Pengetahuan Tentang Persiapan Persalinan. Jurnal Ilmiah Bidan. 3 (1): 61-65.

Mcintosh T (2013). The Concept of Early Labour in the Experience of Maternity in Twentieth Century Britain.Journal Elsevier.

Nilsson L, Thorsell T, Wahn EH, Ekstrom A (2013). Factors Influencing Positive Birth Experiences of First-Time Mothers. Nuring Research and Practice. Http://dx.doi.org/10.1155/2013/349124.
Pinar G, Avsar F, Aslantekin F (2016). Evaluation of the Impact of Childbirth Education Classes in Turkey on Adaptation to pregnancy Process, Concerns About Birth, Rate of Vaginal Birth, and Adaptation to Maternity: A Case Control Study. Sage Journals. https://doi.org/10.1177/1054773816682331.

Rasouli M, Atashsokhan G, Keramat A, Khosravi A, Fooladi E, Mousavi SA (2016). The Impact of Motivational Interviewing on participation in Childbirth Preparation Classes and Having a Natural Delivery: a Randomised Trial. An International Journal of Obstetrics and Gynaecology.

Redshaw M, Henderson J (2013). Fathers' engagement in pregnancy and childbirth: evidence from a national survey. BMC Pregnancy and Childbirth. 13 (70): 1-15.

Soumya SR, Bindu CG (2016). Effect of Supportive Education Intervention Package on Pain and Anxiety During Labour among Primigravida Mothers. International Journal of Applied Research.

Ulstad SO, Halvar H, Sorebo O, Edward L (2016). Motivation, Learning Strategies, and Performance in Physical Education at Secondary School. Advances in Physical Education. http://dx.doi.org/10.4236/ape.2016.61004 